\title{
Life-history variation in the short-lived herb Rorippa palustris: effect of germination date and injury timing
}

\section{Jitka Klimešová · Monika Sosnová • Jana Martínková}

\author{
Erratum to: Plant Ecol \\ DOI 10.1007/s11258-006-9180-x
}

Unfortunately due to a mistake with Figure 2, the author has replaced the same with an updated version as illustrated below:

Life-history of injured plants

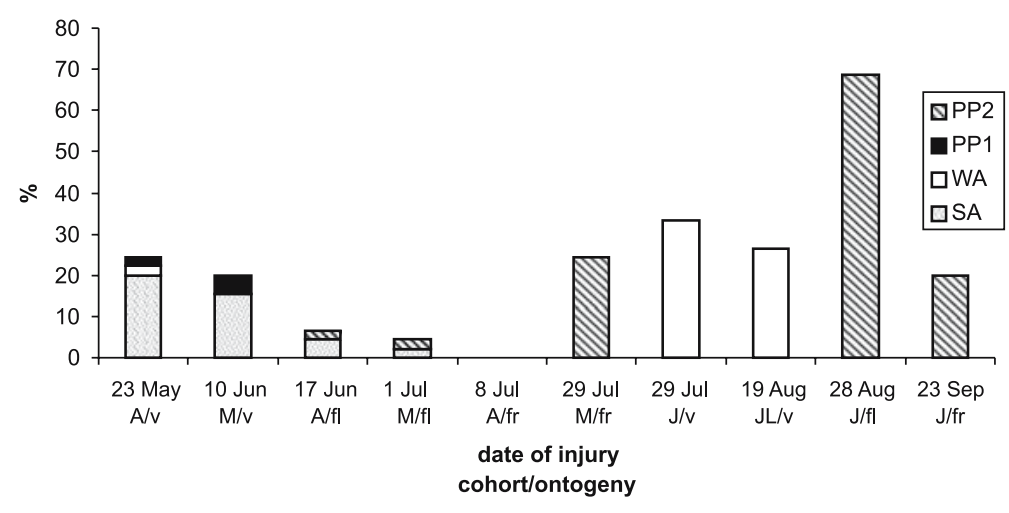

The online version of the original article can be found at http://www.dx.doi.org/10.1007/s11258-006-9180-x

J. Klimešová $(\bowtie) \cdot$ M. Sosnová · J. Martínková Institute of Botany, Czech Academy of Sciences, Dukelská 135, CZ-379 82 Třeboň, Czech Republic e-mail: klimesova@butbn.cas.cz

\section{Sosnová}

Faculty of Biological Sciences, University of South Bohemia, Branišovská 31, CZ-370 05 České

Budějovice, Czech Republic 